\title{
Solubility and Partition Coefficient of Salicylamide in Various pH Buffer Solutions
}

\author{
Dewi Isadiartuti ${ }^{*}$, Noorma Rosita, Esti Hendradi, Firdausiah Fania Dwi Putri, and Frida Magdalena
}

Department of Pharmaceutical Sciences, Faculty of Pharmacy, Universitas Airlangga, Campus C Mulyorejo, Surabaya 60115, Indonesia

\section{*Corresponding author:}

tel: $+62-31-5933150$

email:dewi-i@ff.unair.ac.id

Received: June 7, 2021

Accepted: August 21, 2021

DOI: $10.22146 /$ ijc. 66411

\begin{abstract}
The solubility and partition coefficient are essential physicochemical parameters in developing a pharmaceutical dosage form of medicine. In addition, these parameters help to predict the absorption of an active compound in oral or topical dosage forms. Salicylamide, an active ingredient available in oral and topical dosage forms, is a weak acid $\left(p K_{a} 8.2\right)$ and is sparingly soluble in water. Meanwhile, its solubility and partition coefficients are influenced by the $\mathrm{pH}$ of the environment. The HendersonHasselbalch equation is used to predict solubility- $p H$ and partition- $p H$ profiles at various $p H$ solutions. This study aims to determine salicylamide's solubility and partition coefficient in various $p H(2-11)$. Both tests were carried out in various $p H$ buffer solutions (at a concentration of $0.02 \mathrm{M}$ and 0.2 ionic strength) in a water bath shaker at a temperature of $37 \pm 0.5^{\circ} \mathrm{C}$. In addition, the salicylamide content was determined using the UV spectrophotometer method at the maximum wavelength at each $p H$. The results showed that the solubility increased at $\mathrm{pH} 2-10$, while the partition coefficient value decreased. On the other hand, at $p H 11$, there was an increase in the number of ionized species, but the solubility decreased.
\end{abstract}

Keywords: salicylamide; solubility; partition coefficient; Henderson-Hasselbalch; medicine

\section{- INTRODUCTION}

Salicylamide is an amide obtained from the modification of the salicylic acid carboxyl group by substituting amine compounds. This modification is aimed at minimizing side effects. Furthermore, modifying the molecular structure of compounds with known biological activity is one of the strategies in drug development that aims to obtain new compounds with higher activity, lower half-life, higher levels of comfort, lower toxicity or side effects, and higher selectivity and stability [1-2].

Salicylamide is a weakly acidic compound $\left(\mathrm{pK}_{\mathrm{a}} 8.2\right)$ obtained from salicylate derivatives but not hydrolyzed to salicylates. The salicylamide molecular structure can be seen in Fig. 1. It has an analgesic and antipyretic effect similar to salicylic acetyl acid but the effects are weaker compared to salicylic acid. Salicylamide undergoes firstpass metabolism in the intestinal mucosa to avoid causing inflammation and bleeding in the stomach [3-4].<smiles>NC(=O)c1ccccc1O</smiles>

Fig 1. Molecular structure of salicylamide

Salicylamide is safely used orally and topically, alone or in combination with other medicinal ingredients. When used orally, it transmits various enteral channels, starting from the oral cavity, esophagus, stomach, duodenum, jejunum, ileum, colon, and rectum. Different parts of the gastrointestinal tracts each have a specific acidity $(\mathrm{pH})$, i.e., the oral cavity has a $\mathrm{pH}$ of about 7 , the esophagus between $5-6$, and the stomach around 2-6 during fasting and between 1.5-2 with food. The lower gastrointestinal tract has $\mathrm{pH}$ values approaching neutral or base with the duodenum ranging between 6-6.5, the ileal around 7, the colon between 5.57 , while the rectum has a $\mathrm{pH}$ value of around 7 . In regards to topical use, the skin has a $\mathrm{pH}$ of 4-6. 
Therefore, environmental acidity $(\mathrm{pH})$ affects the solubility and coefficient of a drug partition [5].

The solubility and partition coefficient data of a drug compound are useful for pharmaceutical preparations [1,6-7]. Solubility is the amount of solute of a compound in a saturated state at a specific temperature. In contrast, the partition coefficient states the lipophilicity of a compound at a specific temperature and is expressed as $\log$ P. A compound must be dissolved and absorbed across the biological membrane to have a pharmacological effect [5,8-9].

The solubility of a compound is determined from the compound concentration in equilibrium with the solid phase. The partition coefficient value is measured by determining the equilibrium concentration of the drug compound in the water and oil phases and is formulated in Eq. (1).

$\mathrm{P}=\frac{[\mathrm{C} \text { oil }]}{[\mathrm{C} \text { water }]}$

where $\mathrm{P}$ is the partition coefficient, [C oil] is the concentration of the drug compound in the oil phase, and [C water] is the concentration of the drug compound in the water phase. A drug compound with a high partition coefficient value will be more soluble in the oil phase, while a drug compound with a low partition coefficient value will be more soluble in water. The lipophilicity of a compound will affect the absorption of the compound through the lipid bilayer of the cellular membrane $[5,9]$.

For weakly acidic or alkaline compounds, their solubility and partition coefficients are influenced by environmental $\mathrm{pH}$ [10-11]. Therefore, based on the $\mathrm{pK}_{\mathrm{a}}$ value of the compound and the $\mathrm{pH}$ of the medium, the solubility of a weak acid or base compound can be predicted using the Henderson-Hasselbalch equation. The Henderson-Hasselbalch's equation for weak acid compounds is as follows:

$\mathrm{pH}-\mathrm{pK}_{\mathrm{a}}=\log \left(\frac{\mathrm{s}_{0}-\mathrm{S}}{\mathrm{S}_{0}}\right)$

Moreover, for weak base compounds is as follows:

$\mathrm{pH}-\mathrm{pK}_{\mathrm{a}}=\log \left(\frac{\mathrm{S}_{0}}{\mathrm{~S}_{0}-\mathrm{S}}\right)$

where $S_{0}$ is the total saturation solubility of the compound (ionized and unionized forms), and $\mathrm{S}$ is its solubility in its unionized form. From this formula, the percentage of the ionized and unionized forms of a compound can be predicted. The ionized form is related to the ability to interact with water molecules, so that the greater the number of ionized molecules, the more soluble it is in water. From Eq. (2) and (3), it is known that a weakly acidic compound will dissolve easily in alkaline $\mathrm{pH}$, whereas a weakly alkaline compound will dissolve more easily in acidic $\mathrm{pH}[5,8]$.

Drug bioavailability is influenced by solubility and membrane permeability. High solubility results in a higher diffuse drug concentration gradient $[5,8,13]$, hence accelerating the matrix's dissolution or drug release process. Furthermore, the acidity $(\mathrm{pH})$ of the environment also affects the penetration of drugs through the biological membrane, especially for weak acidic and alkaline drugs. A previous study reported that only the unionized drug fraction transits the biological membrane [5,9]. On the other hand, compounds with $\log$ partition coefficient $(\log \mathrm{P})$ values close to biological membranes tend to penetrate easily [14-16].

The $\log \mathrm{P}$ value required for injection, oral, and transdermal preparations is $\leq 0,0-3$, and $1-3$, respectively [5]. Identifying the drug partition coefficient is essential to predict the concentration of the compound that enters the body and causes pharmacological effects. Furthermore, drug absorption in each organ differs, influenced by the log P-value [17]. For example, optimal absorption in the colon requires a $\log \mathrm{P}$ value of $1.32,1.35$ in the intestine, 2.6 for percutaneous absorption, and sublingual require a $\log \mathrm{P}-$ value of 1.6 to 3.3. Furthermore, the absorption of orally administered drugs is potentially optimized when the $\log \mathrm{P}$ value is close to 1.8. Meanwhile, a value of around $2 \pm 0.7$ is needed to penetrate the central nervous system. Higher $\log P$ values (4-7) tend to cause toxic effects as the drug compounds are stored in fat, which requires a longer time to be excreted from the body [5].

Several researchers have examined the solubility and partition coefficient of salicylamide. Blake et al. [18] examined the correlation of salicylamide solubility in various organic solvents with Abraham's parameter. Laube et al. [19] compared the partition coefficient of 
salicylamide at 2 different temperatures (293.15 and $323.15^{\circ} \mathrm{K}$ ) and 2 different $\mathrm{pH}$ values ( $\mathrm{pH} 5.2$ and 10.3) in various solvent systems. The results show that the partition coefficient value of salicylamide in $n$ octanol/buffer is highly dependent on the temperature and $\mathrm{pH}$ of the environment. Mornar and Jasprica [20] determined the correlation of the $\log \mathrm{P}$ value of salicylamide in various $n$-octanol/phosphate buffer levels at $\mathrm{pH} 7.4$ with nine computer programs. The results showed that only one program was close to the actual conditions, namely the CSlogP program. Other programs showed an error of up to $25 \%$. The experimental results of the partition coefficient value of salicylamide in various levels of $n$-octanol/phosphate buffer $(1: 20 ; 1: 30 ; 1: 70$ : $1: 80)$ at $\mathrm{pH} 7.4$ and temperature of $25{ }^{\circ} \mathrm{C}$ showed an average partition coefficient value $(\log \mathrm{P})$ of $1.38 \pm 0.19$.

The novelty in this research is the availability of data of salicylamide regarding solubility- $\mathrm{pH}$ and partition- $\mathrm{pH}$, which other researchers have not studied. Therefore, this study aims to determine the solubility and partition coefficient of salicylamide in the $\mathrm{pH}$ range of 2-11 associated with the prediction of the HendersonHasselbalch equation. The research was conducted experimentally by adjusting the buffer concentration of $0.02 \mathrm{M}$ and ionic strength of 0.2 , where these two factors can affect the observed parameters [11]. The advantage of testing in experimental conditions is that the results obtained are following the actual conditions [19-20].

\section{- EXPERIMENTAL SECTION}

\section{Materials}

This study was conducted using pharmaceutical grade salicylamide (from PT Riasima Abadi Farma batch XSLS2013P), distilled water, and pro analysis ingredients, including $n$-octanol, $\mathrm{KCl}, \mathrm{HCl}$, citric acid, sodium citrate, $\mathrm{NaH}_{2} \mathrm{PO}_{4} \cdot 2 \mathrm{H}_{2} \mathrm{O}, \mathrm{Na}_{2} \mathrm{HPO}_{4} \cdot 7 \mathrm{H}_{2} \mathrm{O}, \mathrm{Na}_{2} \mathrm{~B}_{4} \mathrm{O}_{7} \cdot 10 \mathrm{H}_{2} \mathrm{O}$, and $\mathrm{NaOH}$.

\section{Instrumentation}

The instruments used in this study were ultravioletvisible spectrophotometer (UV-Vis Cary 50 Conc), $\mathrm{pH}$ meter (GmbH Lab 850), water bath shaker (Memmertz), a set of laboratory glassware such as test tubes, volume pipettes, volumetric flasks, glass beakers, glass funnel, and stirrer.

\section{Procedure}

Determination of the maximum wavelength and standard curve equations of salicylamide at various pH

The maximum wavelength of the salicylamide solution was determined using the UV spectrophotometry method in a working-standard solution of 10.0 and $20.0 \mu \mathrm{g} / \mathrm{mL}$ and different $\mathrm{pH}$ (2.0 to 11.0 ) and measured with a $\mathrm{pH}$ meter. The maximum wavelength scanning was carried out between 200$400 \mathrm{~nm}$, and the peak was determined from the highest absorbance value obtained at each $\mathrm{pH}$. Furthermore, the standard curves of the solutions were determined at the level of $10.0 ; 16.0 ; 20.0 ; 30.0$; and $40.0 \mu \mathrm{g} / \mathrm{mL}$. The concentration of salicylamide solution was determined at the maximum wavelength of each $\mathrm{pH}$, and a standard curve regression equation was made together with the correlation coefficient $\left(r_{\text {count }}\right)$.

Determination of the solubility of salicylamide in various $\mathrm{pH}$ buffer solutions $0.02 \mathrm{M}$ with ionic strength of 0.2 at $37 \pm 0.5^{\circ} \mathrm{C}$

An excess amount of salicylamide was placed into a vial containing $5 \mathrm{~mL}$ of a buffer solution of $0.02 \mathrm{M}$ with an ionic strength of 0.2 . After that, the container was placed into a water bath shaker at $37 \pm 0.5^{\circ} \mathrm{C}$ and shaken at the speed of 150 times/min until a saturated solubility was formed. Afterward, the mixture was observed for $10 \mathrm{~min}$. After that, $2 \mathrm{~mL}$ of the sample was taken with an injection syringe while the solution was filtered with $0.45 \mu \mathrm{m}$ Whatman filter paper. The extracted filtrate was diluted using a buffer solution according to the respective $\mathrm{pH}$, and the salicylamide levels were determined using a UV spectrophotometer at maximum wavelength. Meanwhile, for each $\mathrm{pH}$, the solubility test was replicated 3 times.

Determination of the partition coefficient of salicylamide in various $\mathrm{pH}$ buffer solutions $0.02 \mathrm{M}$ with ionic strength of 0.2 at $37 \pm 0.5^{\circ} \mathrm{C}$

The saturated $n$-octanol buffer solution containing $200 \mu \mathrm{g} / \mathrm{mL}$ salicylamide and the $n$-octanol saturated 
buffer in equal proportions was mixed in a $5 \mathrm{~mL}$ vial container. The container was placed into a water bath shaker at $37 \pm 0.5{ }^{\circ} \mathrm{C}$ and shaken at 150 times/min until equilibrium was attained between the salicylamide concentration in the water and the oil phase. After that, the aqueous phase of the solution was separated from the $n$-octanol oil phase. The salicylamide content in the buffer solution was determined by the UV spectrophotometer method at the maximum wavelength of each $\mathrm{pH}$ (2.0 to 10.0). Meanwhile, the partition coefficient test was replicated 3 times for each $\mathrm{pH}$.

The mean solubility and the $\log$ value of the partition coefficient of salicylamide from three measurements at each $\mathrm{pH}$ were analyzed by one-way ANOVA statistic ( $\alpha$ 0.05) followed by the Post-Hoc Least Significant Difference (LSD) test.

\section{- RESULTS AND DISCUSSION}

\section{The Maximum Wavelength and Standard Curve Equations of Salicylamide at Various pH}

Determining the effect of $\mathrm{pH}$ on salicylamide solubility and partition coefficient began with determining the maximum wavelength and preparing a regression equation from the standard curve. The results obtained are presented in Table 1.

The maximum wavelength of the salicylamide solution from acidic to alkaline $\mathrm{pH}$ exhibits a shift to a longer wavelength. This shift is influenced by the presence of a chromophore group conjugated to a double bond. At alkaline $\mathrm{pH}$, salicylamide undergoes ionization and produces a conjugated chromophore. Therefore, the energy required to transition from the inner electronic energy level to the external decreases, and the maximum wavelength becomes longer [21].

The standard curve regression equation (Table 1) was used to determine the salicylamide content in the water phase, solubility, and partition coefficient in the $0.02 \mathrm{M}$ buffer solution with $\mathrm{pH}$ ranging from 2.0 to 11.0. Based on the partition coefficient value $\left(\mathrm{r}_{\text {count }}\right.$ ) obtained and $\mathrm{V}_{\mathrm{x} 0}$ value of less than $5 \%$, there was a linear relationship between salicylamide concentrations at each $\mathrm{pH}$ in the range of $10-40 \mu \mathrm{g} / \mathrm{mL}$ and absorbance.

\section{The Solubility of Salicylamide in Various pH Buffer Solutions}

The solubility of salicylamide in various $\mathrm{pH}$ solutions was feasibly determined until the equilibrium between the solid and liquid phases was reached, after 7 $\mathrm{h}$ of shaking in a water bath at $37 \pm 0.5^{\circ} \mathrm{C}$, without increasing the concentration. Furthermore, the solubility test results are shown in Fig. 2.

Based on the Bronsted-Lowry concept proposed in 1923 , acidic compounds give protons or $\mathrm{H}^{+}$, while basic compounds accept protons or $\mathrm{H}^{+}$[22]. Salicylamide is a weak acidic compound with a $\mathrm{pK}_{\mathrm{a}}$ value of 8.2. Structurally, salicylamide has an ${ }^{-} \mathrm{OH}$ group capable of releasing protons or $\mathrm{H}^{+}$. Hence, it is classified as an acidic compound. Furthermore, in the aqueous solution, salicylamide undergoes dissociation depending on the $\mathrm{pH}$ value of the environment. The percentage of ionized

Table 1. The maximum wavelength and standard curve regression equation of salicylamide solution in various $\mathrm{pH}$

\begin{tabular}{lccccc}
\hline Buffer solution & $\begin{array}{c}\text { Salicylamide solution } \\
\text { in a pH buffer }\end{array}$ & $\begin{array}{c}\lambda_{\max } \\
(\mathrm{nm})\end{array}$ & Regression equation & $\mathrm{r}_{\text {count }}$ & $\mathrm{V}_{\mathrm{x} 0}$ \\
\hline $\mathrm{KCl}$ & 2.0 & 298 & $\mathrm{Y}=0.025 \mathrm{X}+0.021$ & 0.9987 & $0.17 \%$ \\
citrate & 3.0 & 299 & $\mathrm{Y}=0.026 \mathrm{X}+0.011$ & 0.9994 & $0.10 \%$ \\
citrate & 4.0 & 299 & $\mathrm{Y}=0.025 \mathrm{X}+0.014$ & 0.9996 & $0.12 \%$ \\
citrate & 5.0 & 299 & $\mathrm{Y}=0.026 \mathrm{X}+0.006$ & 0.9996 & $0.06 \%$ \\
citrate & 6.0 & 299 & $\mathrm{Y}=0.025 \mathrm{X}+0.016$ & 0.9992 & $0.14 \%$ \\
phosphate & 7.0 & 300 & $\mathrm{Y}=0.025 \mathrm{X}+0.018$ & 0.9991 & $0.15 \%$ \\
phosphate & 8.0 & 305 & $\mathrm{Y}=0.022 \mathrm{X}+0.024$ & 0.9985 & $0.21 \%$ \\
boric & 9.0 & 310 & $\mathrm{Y}=0.024 \mathrm{X}+0.017$ & 0.9994 & $0.15 \%$ \\
boric & 10.0 & 327 & $\mathrm{Y}=0.035 \mathrm{X}+0.025$ & 0.9997 & $0.22 \%$ \\
phosphate & 11.0 & 327 & $\mathrm{Y}=0.044 \mathrm{X}+0.015$ & 0.9997 & $0.13 \%$ \\
\hline
\end{tabular}




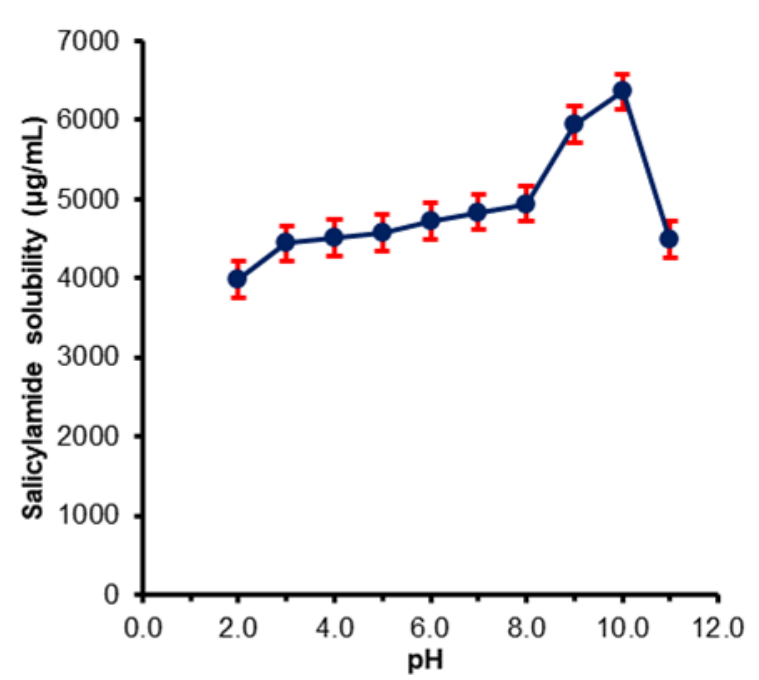

Fig 2. Solubility-pH profile of salicylamide in various $\mathrm{pH}$ buffer solutions at a temperature of $37 \pm 0.5{ }^{\circ} \mathrm{C}(\mathrm{n}=3)$

Table 2. The percentage of ionized and unionized salicylamide molecules in various $\mathrm{pH}$ buffer solutions based on the calculation of the Henderson-Hasselbalch equation

\begin{tabular}{rcc}
\hline $\mathrm{pH}$ & $\begin{array}{c}\text { Percentage of } \\
\text { ionized molecules }\end{array}$ & $\begin{array}{c}\text { Percentage of unionized } \\
\text { molecules }\end{array}$ \\
\hline 2.0 & 0.01 & 99.99 \\
3.0 & 0.01 & 99.99 \\
4.0 & 0.01 & 99.99 \\
5.0 & 0.06 & 99.94 \\
6.0 & 0.63 & 99.37 \\
7.0 & 5.94 & 94.06 \\
8.0 & 38.69 & 61.31 \\
9.0 & 86.32 & 13.68 \\
10.0 & 98.44 & 1.56 \\
11.0 & 99.84 & 0.16 \\
\hline
\end{tabular}

and unionized forms of salicylamide molecules in the various $\mathrm{pH}$ buffer solutions calculated using the Henderson-Hasselbalch equation is presented in Table 2.

Based on the Henderson-Hasselbalch equation's calculation at a $\mathrm{pH}$ value equal to $\mathrm{pK}_{\mathrm{a}}$, a drug compound has the same percentage of the ionized and unionized forms. For a weak acid, when the $\mathrm{pH}$ of the solution is 2 units below the $\mathrm{pK}_{\mathrm{a}}, 0.01 \%$ of the compound is in the ionized form. Whereas, when the $\mathrm{pH}$ is 2 units above the $\mathrm{pK}_{\mathrm{a}}, 99.99 \%$ is in the ionized form [8].

The theoretical calculation of the ionized and unionized forms of salicylamides molecules using the
Henderson-Hasselbalch equation at a $\mathrm{pH}$ one unit below the $\mathrm{pK}_{\mathrm{a}}$ and a pH below or at 7.0 to 2.0 , showed that the percentage of the unionized form of salicylamide was more significant than the ionized form. Conversely, at a $\mathrm{pH}$ one unit above the $\mathrm{pK}_{\mathrm{a}}$ and a $\mathrm{pH}$ above or at 9.0 to 11.0 , it showed that the percentage of the ionized form was more significant than the unionized form. Furthermore, the ionized salicylamide easily interacted with the water medium, increasing solubility with the increasing ionization. The ionized form easily dissolves in the aqueous phase because water is a polar compound. The positive ion (cation) attracts the partial negative end of the water molecule, while the negative ion (anion) attracts the positive end of the water molecule [23]. At $\mathrm{pH} 11.0$, where the ionic percentage was $99.84 \%$, the salicylamide solubility decreased due to the amide group in its structure. Compounds with an amide group are generally susceptible to hydrolysis catalyzed by specific bases $\left({ }^{-} \mathrm{OH}\right)$. Moreover, at $\mathrm{pH}$ 11.0, salicylamide potentially underwent hydrolysis with a specific base catalyst, thereby decreasing its levels [24].

Based on the one-way ANOVA statistical test at $\alpha$ $=0.05$, the significance value was 0.000 . The statistical test was continued with the Post-Hoc LSD test, which indicated that the solubility of salicylamide at various $\mathrm{pH}$ values was significantly different except at $\mathrm{pH} 4.0$ and 5.0. The increase in solubility as the $\mathrm{pH}$ approached 10.0 is related to the dissociation of salicylamide at each $\mathrm{pH}$ of the solution to form ionized and unionized molecules.

\section{The Partition Coefficient of Salicylamide in Various pH Buffer Solutions}

The partition coefficient was determined using water phases of the buffer solution at different $\mathrm{pH}$ and $n$-octanol as the oil phase. The latter is used for several reasons, including the presence of a long non-polar hydrocarbon chain and a polar hydroxyl group. Therefore, it is closer to the lipid bilayer biological membrane. In addition, $n$-octanol is inert and less toxic. Besides that, $n$-octanol provides no significant absorption at ultraviolet wavelengths [5,13]. The partition coefficient log value obtained in the $\mathrm{pH}$ of the buffer solution is shown in Fig. 3. 


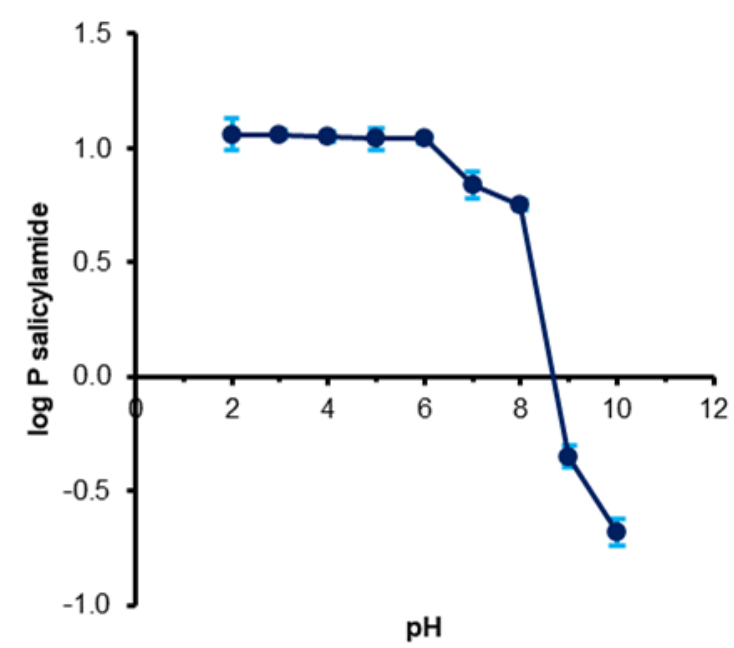

Fig 3. Partition- $\mathrm{pH}$ profile salicylamide in various $\mathrm{pH}$ buffer solutions at temperature of $37 \pm 0.5^{\circ} \mathrm{C}(\mathrm{n}=3)$

The partition coefficient value at each $\mathrm{pH}$ is influenced by the number of ionized and unionized molecular forms. At $\mathrm{pH}$ 2.0-6.0, the amount of salicylamide in the unionized form was almost the same. Hence, solubility in the water and oil phases was almost the same. Also, the log value of the partition coefficient at $\mathrm{pH} 2.0$ to 6.0 had no significant difference. At $\mathrm{pH} 7.0$, the number of unionized molecules dropped to $94.06 \%$, whereas at 8.0, when the $\mathrm{pH}$ value of the solution approached the $\mathrm{pK}_{\mathrm{a}}$ value of salicylamide, the unionized molecules were nearly equal to the amount of the ionized molecules. Furthermore, as the $\mathrm{pH}$ of the solution became more alkaline at $\mathrm{pH} 9$ and 10, the number of unionized forms decreased to $13.68 \%$ and $1.56 \%$, respectively. When the number of unionized molecules decreases compared to the ionized molecules, the salicylamide compound ionizes completely (at 2 units above the $\mathrm{pK}_{\mathrm{a}}$ value, i.e., $\mathrm{pH}$ 10.0), the partition coefficient gradually reduces due to the decreased solubility in the oil phase.

Statistical analysis was carried out using the one-way ANOVA with $\alpha=0.05$, giving a significance value of 0.000. A further test was done with the Post-Hoc Least Significant Difference (LSD) test and indicated the partition coefficient value in $\mathrm{pH}$ ranging from 2.0 to 6.0 had no significant difference. Meanwhile, at $\mathrm{pH} 7.0-10.0$, significant differences were recorded in $\log \mathrm{P}$ values of the partition coefficient.
The experimental results of the solubility and partition coefficient of salicylamide in buffer solutions of $\mathrm{pH}$ 2-10 correlated with the Henderson-Hasselbalch equation. Salicylamide is a weak acid compound with a $\mathrm{pK}_{\mathrm{a}}$ value of 8.2 that showed increased solubility at $\mathrm{pH}$ of above 8 , while the partition coefficient (log P value) decreased due to the dominant ionic form of salicylamide under these conditions. The results of this study are in line with the findings of Laube et al. [19], who examined the salicylamide partition coefficient at $\mathrm{pH} 5.2$ and 10.3. It was reported that increasing $\mathrm{pH}$ causes a decrease in the value of the partition coefficient. The decrease can be explained by observing the amount of ionized salicylamide at $\mathrm{pH} 10.3$, which was higher than at $\mathrm{pH}$ 5.2. Thus, the increasing ionic form causes the solubility of salicylamide in water to increase. In contrast, it causes a decrease in the value of the partition coefficient. As a result, the partition coefficient value at $\mathrm{pH} 10.3$ was less than 1 , indicating that more compounds were in the water phase.

When salicylamide compounds are taken orally, it transits the digestive tract in a $\mathrm{pH}$ range of around 1 to 6. Meanwhile, when used topically, it is localized in the skin with $\mathrm{pH}$ ranging from around $4-6[8,17]$. Based on the results, salicylamide compounds at $\mathrm{pH} 6$ have a $4721.33 \pm 63.45 \mu \mathrm{g} / \mathrm{mL}$ solubility and a $\log \mathrm{P}$ value of $1.04 \pm 0.02$. Salicylamide dissolved in the ionized and unionized forms in sufficient quantities at the absorption site is the driving force for absorption across the biological membrane by passive diffusion. The unionized form is the molecular form that can penetrate the membrane. At $\mathrm{pH} \mathrm{6,} \mathrm{salicylamide} \mathrm{will} \mathrm{be} \mathrm{in} \mathrm{the}$ molecular form of about $99.37 \%$. In the process of the absorption of drug compounds through biological membranes and the solubility of drug compounds, the value of the partition coefficient is also affected. The mucosa in the body is lipophilic, having a log partition coefficient value of about \pm 2 . Therefore, salicylamide with a partition coefficient value close to the log partition coefficient value at the absorption site will absorb well. Therefore, it is estimated that at this $\mathrm{pH}$, salicylamide compounds are sufficiently absorbed in the 
gastrointestinal tract when used orally or penetrate the skin membrane when used topically.

\section{- CONCLUSION}

Salicylamide is a weak acid compound with a $\mathrm{pK}_{\mathrm{a}}$ value of 8.2 , so its solubility is affected by the $\mathrm{pH}$ of the environment. Based on predictions using the HendersonHasselbalch equation, at $2 \mathrm{pH}$ units above the $\mathrm{pK}_{\mathrm{a}}$ value of salicylamide, more than $98 \%$ of salicylamide is in the ionized form, and the percentage of ionized salicylamide increases. The ionized form correlates with the ease of solubility in water. On the other hand, as the percentage of ionized salicylamide increases, the solubility of salicylamide in the oil phase decreases. Research shows that increasing the $\mathrm{pH}$ from $\mathrm{pH} 2$ to $\mathrm{pH} 10$ increases the solubility of salicylamide in water, but at $\mathrm{pH} 11$, its solubility decreases. On the other hand, an increase in $\mathrm{pH}$ will decrease the log value of the partition coefficient. From this research, data on the solubility-pH and partition-pH profiles of salicylamide were obtained, which will be helpful in the development of salicylamide preparations and in predicting their bioavailability.

\section{- ACKNOWLEDGMENTS}

The authors thank the Faculty of Pharmacy for providing facilities and infrastructure in this research. The oral presentation was delivered at the USIM International Health Conference 2020, 16-17 December 2020 .

\section{- AUTHOR CONTRIBUTIONS}

DI, NR, EH, FFDP, and FM conducted the experiment. DI, NR, EH, FFDP, and FM conducted the DFT calculations. DI, NR, and EH wrote and revised the manuscript. All authors agreed to the final version of this manuscript.

\section{- REFERENCES}

[1] Hughes, J.P., Rees, S., Kalindjian, S.B., and Philpott, K.L., 2011, Principles of early drug discovery, $B r . J$. Pharmacol., 162 (6), 1239-1249.

[2] National Center for Biotechnology Information, 2020, PubChem Compound Summary for CID 5147, Salicyl amide, https://pubchem.ncbi.nlm.nih.gov/
compound/Salicylamide, accessed on 15 December 2020.

[3] Rizk, M., and Abdel-Rahman, M.S., 1994, Salicylamide reverses the aspirin-antagonistic effect of salicylic acid on rat platelet cyclooxygenase, Prostaglandins, Leukotrienes Essent. Fatty Acids, 51 (5), 363-367.

[4] Brayfield, A., 2014, Martindale: The Complete Drug Reference, $38^{\text {th }}$ Ed., Pharmaceutical Press ( $\left.\mathrm{PhP}\right)$, London, UK.

[5] Shargel, L., and Yu, A.B.C., 2016, Applied Biopharmaceutics and Pharmacokinetics, $7^{\text {th }}$ Ed., Mc Graw-Hill Education, New York, 263-264, 425-437.

[6] Xiao, C., Zhu, L., Li, R., Pang, L., Zhu, S., Ma, J., Du, L., and Jin, Y., 2020, Electroporation-enhanced transdermal drug delivery: Effects of $\log \mathrm{P}, \mathrm{pK}_{\mathrm{a}}$, solubility, and penetration time, Eur. J. Pharm. Sci., 151, 105410.

[7] Zhang, Q., Wang, Z., Xue, H., Huang, B., Lin, Z., and Cai, Z., 2021, Determination and comparison of the solubility, oil-water partition coefficient, intestinal absorption, and biliary excretion of carvedilol enantiomers, AAPS PharmSciTech, 22 (1), 43.

[8] Plöger, G.F., Hofsäss, M.A., and Dressman, J.B., 2018, Solubility determination of active pharmaceutical ingredients which have been recently added to the list of essential medicines in the context of the biopharmaceutics classification system-biowaiver, J. Pharm. Sci., 107 (6), 1478-1488.

[9] Isadiartuti, D., Budiati, T., and Martodihardjo, S., 2015, Bioavailability study of physical mixture of carbamazepine and amino acid, Asian J. Pharm. Clin. Res., 8 (3), 92-95.

[10] Pobudkowska, A., and Domańska, U., 2014, Study of $\mathrm{pH}$ dependent drugs solubility in water, Chem. Ind. Chem. Eng., 20 (1), 115-126.

[11] Hamed, R., Awadallah, A., Sunoqrot, S., Tarawneh, O., Nazzal, S., AlBaraghthi, T., Al Sayyad, J., and Abbas, A., 2016, pH-Dependent solubility and dissolution behavior of carvedilol-Case example a weakly basic BCS class II drug, AAPS PharmSciTech, 17 (2), 418-426. 
[12] Loh, Z.H., Samanta, A.K., and Heng, P.W.S., 2015, Overview of milling techniques for improving the solubility of poorly water-soluble drugs, Asian J. Pharm. Sci., 10 (4), 255-274.

[13] Sharma, T., and Jana, S., 2020, Investigation of molecular properties that influence the permeability and oral bioavailability of major $\beta$-boswellic acids, Eur. J. Drug Metab. Pharmacokinet., 45 (2), 243-255.

[14] Nugrahaeni, F., Hariyadi, D.M., and Rosita, N., 2018, Partition coefficient and glutathione penetration of topical antiaging: Preformulation study, Int. J. Drug. Delivery Technol., 8 (2), 39-43.

[15] Rosita, N, Meitasari, V.A., Rianti, M.C., Hariyadi, D.M., and Miatmoko, A., 2019, Enhancing skin penetration of epigallocatechin gallate by modifying partition coefficient using reverse micelle method, Ther. Delivery, 10 (7), 409-417.

[16] Czyrski, A., 2019, Determination of the liphophilicity of ibuprofen, naproxen, ketoprofen, and flurbiprofen with thin-layer chromatography, J. Chem., 2019, 3407091.

[17] Li, W., Quan, P., Zhang, Y., Cheng, J., Liu, J., Cun, D., Xiang, R., and Fang, L., 2014, Influence of drug physicochemical properties on absorption of water insoluble drug nanosuspensions, Int. J. Pharm., 460 (1-2), 13-23.
[18] Blake-Taylor, B.H., Deleon, V.H., Acree, W., and Abraham, M.H., 2007, Mathematical correlation of salicylamide solubilities in organic solvents with the Abraham solvation parameter model, Phys. Chem. Liq., 45 (4), 389-398.

[19] Laube, F., Klein, T., and Sadowski, G., 2015, Partition coefficient of pharmaceuticals as functions of temperatures and $\mathrm{pH}$, Ind. Eng. Chem. Res., 54 (15), 3968-3975.

[20] Medić-Sarić, M., Mornar, A., and Jasprica, X., 2004, Lipophilicity study of salicylamide, Acta Pharm., 54 (2), 91-101.

[21] Pavia, D.L., Lampman, G.M., Kriz, G.S., and Vyvyan, J.R., 2015, Introduction to Spectroscopy, $5^{\text {th }}$ Ed., Cengage Learning, Washington, 29-30.

[22] Helmenstine, A.M., 2019, Bronsted Lowry Theory of Acids and Bases, https://thoughtco.com/bronstedlowry-theory-of-acids-and-bases-4127201, accessed on Aug. 27, 2020.

[23] Vepuri, S.B., Anbazhagan, S., Divya, D., and Padmini, D., 2013, A review on supramolecular chemistry in drug design and formulation research, Indones. J. Pharm., 24 (3), 131-150.

[24] Hibbert, F., and Sellens, R.J., 1988, Intramolecular participation by an amide group in ester hydrolysis, J. Chem. Soc. Perkin Trans., 2 (3), 399-402. 